\title{
Atividade alelopática de extrato de sementes de juazeiro
}

\author{
Maria de Fátima B Coelho; Sandra SS Maia; Andreya K Oliveira; Francisco EP Diógenes \\ UFERSA, Depto. Fitotecnia, C. Postal 137, 59625-900 Mossoró-RN; coelhomfstrela@gmail.com
}

\section{RESUMO}

Alelopatia é a liberação de substâncias vegetais inibidoras ou estimulantes no ambiente, podendo estar presente nas sementes de algumas espécies. O objetivo neste trabalho foi avaliar o potencial alelopático do extrato de sementes de juazeiro (Ziziphus joazeiro Mart.) na germinação de sementes de alface (Lactuca sativa $\mathrm{L}$ ). O experimento foi conduzido em delineamento inteiramente casualizado com quatro repetições e cinco tratamentos $(0,25,50,75$ e $100 \%$ de concentração do extrato bruto). $\mathrm{O}$ extrato bruto foi obtido após a extração de $50 \mathrm{~g}$ de sementes e agitação em liquidificador com 500 $\mathrm{mL}$ de água. Os resultados mostraram efeito alelopático do extrato dependendo da concentração. As maiores concentrações do extrato de sementes de juazeiro afetaram a percentagem e velocidade de germinação e as menores proporcionaram plântulas anormais. Portanto, o extrato apresentou efeito alelopático desfavorável à germinação de sementes de alface.

Palavras-chave: Ziziphus joazeiro, alelopatia, alface.

\section{ABSTRACT}

\section{Allelopatic activity of juazeiro seed extract}

Allelopathy is the release of plant substances that inhibit or act as stimulants in the environment, and may be present in the seeds of some species. The objective of this work was to evaluate the allelopatic activity of the extract of juazeiro (Ziziphus joazeiro Mart.) seeds on the germination of lettuce (Lactuca sativa L.) seeds. We utilized the randomized design with four replications and five treatments $(0,25,50,75$ and $100 \%$ of concentration of the crude extract). The crude extract was obtained after the extraction of 50 $\mathrm{g}$ of seeds, shaking them with $500 \mathrm{~mL}$ of water in a blender. The results showed allelopatic effect, proportional to the increase of the concentration of the extract. The highest concentrations of seed extract of juazeiro affected the percentage and speed of germination and the lowest concentrations caused abnormal seedlings on lettuce seed germination. Therefore, the extract presented an allelopatic effect, unfavorable to the germination of lettuce seeds.

Keywords: Ziziphus joazeiro, allelopathy, lettuce.

(Recebido para publicação em 16 de setembro de 2009; aceito em 17 de janeiro de 2011) (Received on September 16, 2009; accepted on January 17, 2011)

$\mathrm{O}^{\mathrm{s}}$ juazeiro (Ziziphus joazeiro) é uma das espécies endêmica do bioma caatinga e é utilizado na medicina popular como expectorante, no tratamento de bronquites e de ulceras gástricas, na fabricação de cosméticos, xampus anticaspa e creme dental, na alimentação de animais principalmente nos períodos de seca além de apresentar importância econômica, social, e ecológica (Lorenzi \& Matos 2002; Matos, 2000). Suas flores são importantes fontes de recurso alimentar para abelhas indígenas sem ferrão da tribo Meliponini, as quais são utilizadas na meliponicultura, sendo atividade alternativa de renda para produtores de algumas áreas de Caatinga (Nadia et al., 2007). O seu uso em xampus deve-se à presença de saponinas em várias partes da planta, substâncias estas com efeito alopático reconhecido em vários estudos (Maraschin-Silva \& Aquila, 2005, 2006; Gusman et al., 2008). Devido à contínua devastação que o juazeiro vem sofrendo em seu ambiente natural (Matos, 2000), é preciso estimular seu cultivo para garantir sua permanência nos sertões.

A alelopatia é um fenômeno químico ecológico no qual metabólitos secundários, produzidos por uma espécie vegetal, são liberados e interferem na germinação e/ou no desenvolvimento de outras plantas num mesmo ambiente, proporcionando maior adaptação evolutiva (Taiz \& Zeiger, 2004). Num sentido amplo, os efeitos alelopáticos referem-se tanto à inibição quanto ao estímulo de desenvolvimento de outros organismos (Rice, 1984).

As substâncias alelopáticas pertencem a diferentes categorias de compostos secundários e os recentes avanços na química de produtos naturais, métodos de extração e isolamento estão contribuindo para a identificação destas substâncias inibitórias (Ferreira \& Áquila, 2000).

O potencial alelopático desses compostos pode ser pesquisado por meio de extratos aquosos e/ou alcoólicos derivados tanto de plantas cultivadas quanto de medicinais. Trabalhos nesse sentido apontam que houve atividade alelopática e citotóxica dos extratos aquosos de espinheira-santa (Maytenus ilicifolia Mart. Ex Reiss.) sobre sementes de alface (Souza et al., 2005). O extrato metanólico das folhas de Caryocar brasiliense Camb. apresentou ação inibitória em diferentes concentrações sobre a germinação de sementes de Panicum maximum, com valores de inibição variando de 50 até $75 \%$ (Moreira et al., 2009).

Vários estudos foram conduzidos ultimamente em plantas arbóreas tais como Ouratea spectabilis, Pouteria ramiflora, Qualea grandiflora e Stryphnodendron adstringens (Silva et al., 2006), Ocotea odorifera (Vell.) Rohwer (Carmo et al., 2007), Pinus taeda (Sartor et al., 2009) visando identificar propriedades alelopáticas em espécies com potencial para compor sistemas agroflorestais e silvipastoris tanto no Brasil (Borges et al., 1993; Carmo et al., 2007; Jacobi \& Ferreira, 1991) como em outros países (Gonzáles et al., 1995; Zhang, 1993).

Para avaliar se uma planta apresenta 
alelopatia são realizados bioensaios de germinação de sementes de espécies cultivadas de boa qualidade, como tomate (Lycopersicum esculentum) e alface (Lactuca sativa), pois são facilmente encontradas e bastante sensíveis a vários aleloquímicos. De acordo com Sousa (2005), a principal vantagem do uso de alface como alvo de estudos alelopáticos reside na sensibilidade das sementes da espécie, pois mesmo em baixas concentrações de aleloquímicos o processo de germinação pode ser comprometido. Além disso, a germinação é rápida, em aproximadamente $24 \mathrm{~h}$, possui crescimento linear, é insensível às diferenças de $\mathrm{pH}$ em ampla faixa de variação e aos potenciais osmóticos das soluções (Rice, 1984).

No presente trabalho foi avaliado o potencial alelopático do extrato aquoso obtido de sementes de juazeiro na germinação de sementes de alface.

\section{MATERIAL E MÉTODOS}

Frutos maduros de juazeiro foram coletados em árvore no Câmpus da UFERSA em maio de 2008 e para o bioensaio foram utilizadas sementes de alface da variedade "Mônica SF FI". O extrato bruto foi obtido após a extração de $50 \mathrm{~g}$ de sementes por lavagem dos frutos e agitação por um minuto com $500 \mathrm{~mL}$ de água destilada em liquidificador, como preconizado por França et al. (2008). O material foi filtrado em peneira forrada com gaze e algodão. A partir do extrato bruto foram feitas diluições em água destilada para obter as concentrações (v/v) de 25, 50, 75 e $100 \%$. O efeito dos extratos foi comparado com o controle (água destilada, considerada $0 \%$ ).

$\mathrm{O}$ delineamento experimental foi inteiramente casualizado com cinco tratamentos (concentrações de 0, 25, 50,75 e $100 \%$ do extrato bruto) e quatro repetições de 20 sementes de alface. Em cada parcela experimental (placa de Petri de nove centimetros de diâmetro) foram colocados $5 \mathrm{~mL}$ do extrato sobre uma folha de papel-filtro (previamente autoclavado), suficiente para umedecer o papel e, em seguida foram distribuídas uniformemente, com o auxílio de uma pinça 20 sementes de alface sobre o papel filtro. As placas foram acondicionadas em câmara de germinação com temperatura a $25^{\circ} \mathrm{C}$ e fotoperíodo de 12 $\mathrm{h}$, durante sete dias.

A contagem de sementes germinadas foi realizada a cada $12 \mathrm{~h}$ a partir da semeadura. Foram consideradas germinadas as sementes que apresentaram protrusão radicular com cerca de $2 \mathrm{~mm}$, pois segundo Hartmann et. al. (2001) esta é a primeira evidência da germinação, e vários estudos de alelopatia utilizando alface adotaram este critério (Souza et al., 2005; Ferreira et al., 2007; Gusman et al., 2008). No sétimo dia após a semeadura, foi realizada a avaliação das plântulas, classificando-as em normais ou anormais, segundo critérios descritos em Brasil (1992).

$\mathrm{O}$ índice de velocidade de germinação foi calculado de acordo com Maguire (1962), considerando em vez de número de dias após a semeadura, o número de horas:

$$
I V G=\frac{G_{1}+G_{2}+G_{3}+\ldots . G_{n}}{N_{1}+N_{2}+N_{3}+\ldots N_{n}}
$$

Onde, $\mathrm{IVG}=$ índice de velocidade de germinação; $\mathrm{G}_{1}=$ porcentagem de germinação na leitura $1 ; \mathrm{N}_{1}=$ numero de horas para alcançar a germinação $\mathrm{G}_{1}$.

As análises estatísticas foram feitas no Sistema de Análises Estatísticas e Genéticas-SAEG (Ribeiro Junior, 2001).

\section{RESULTADOS E DISCUSSÃO}

A germinação das sementes de alface foi afetada pelas concentrações de 75 e $100 \%$ do extrato de sementes de juazeiro, enquanto as concentrações inferiores ou iguais a $50 \%$ proporcionaram a mesma percentagem de germinação e índice de velocidade de germinação que a testemunha (Tabela 1). Embora não tenham afetado a percentagem de germinação, estas concentrações do extrato causaram alta percentagem de plântulas anormais, evidenciando que os extratos de sementes de juazeiro têm efeito alelopático na germinação de sementes de alface. As plântulas anormais apresentaram as extremidades da raiz primária necrosadas, ausência de epicótilo, geotropismo negativo, sementes intumescidas e apenas a radícula.

Aires et al. (2005) também observaram que os extratos aquosos dos frutos de lobeira (Solanum lycocarpum) causaram redução da germinação de sementes de gergelim (Sesamum indicum) e na plântula houve inibição do crescimento radicular e necrose nas raízes. Jacobi \& Ferreira (1991) verificaram que os extratos de frutos verdes e maduros de maricá (Mimosa bimucronata) não inibiram a germinação, porém os verdes inibiram o crescimento da raiz primária de alface, arroz, cenoura, chicória, couve, pepino, repolho e tomate. A raiz primária de alface mostrou-se, portanto, mais sensível aos compostos secundários presentes nos extratos.

Anormalidades em plântulas de alface também foram observadas por Felix et al. (2007) com o uso de extratos aquosos de Amburana cearensis e por Gatti et al. (2004) com os extratos aquosos de diferentes partes de Aristolochia esperanzae. A avaliação da anormalidade das plântulas é instrumento valioso nos experimentos de alelopatia e a necrose da

Tabela 1. Características de sementes de alface submetidas a diversas concentrações do extrato de sementes de juazeiro (characteristics of lettuce seeds submitted to concentrations of the juazeiro seed extract). Mossoró, UFERSA, 2008.

\begin{tabular}{ccccc}
\hline $\begin{array}{c}\text { Concentração } \\
\text { do extrato } \\
(\%)\end{array}$ & $\begin{array}{c}\text { Germinação } \\
\mathbf{( \% )}\end{array}$ & $\begin{array}{c}\text { Índice de veloci- } \\
\text { dade de germi- } \\
\text { nação }\end{array}$ & $\begin{array}{c}\text { Plântulas } \\
\text { normais } \\
(\mathbf{\%})\end{array}$ & $\begin{array}{c}\text { Plântulas } \\
\text { anormais } \\
\mathbf{( \% )}\end{array}$ \\
\hline 0 & $95,00 \mathrm{a}$ & $19,0 \mathrm{a}$ & $71,25 \mathrm{a}$ & $23,75 \mathrm{~b}$ \\
25 & $91,25 \mathrm{a}$ & $18,3 \mathrm{a}$ & $17,50 \mathrm{~b}$ & $73,75 \mathrm{a}$ \\
50 & $93,75 \mathrm{a}$ & $18,7 \mathrm{a}$ & $7,50 \mathrm{c}$ & $86,25 \mathrm{a}$ \\
75 & $8,75 \mathrm{~b}$ & $1,8 \mathrm{~b}$ & $0 \mathrm{c}$ & $8,75 \mathrm{a}$ \\
100 & $12,50 \mathrm{~b}$ & $2,5 \mathrm{~b}$ & $0 \mathrm{c}$ & $12,50 \mathrm{bc}$ \\
\hline $\mathrm{CV}(\%)$ & $18 \%$ & $12 \%$ & $23 \%$ & $22 \%$ \\
\hline
\end{tabular}




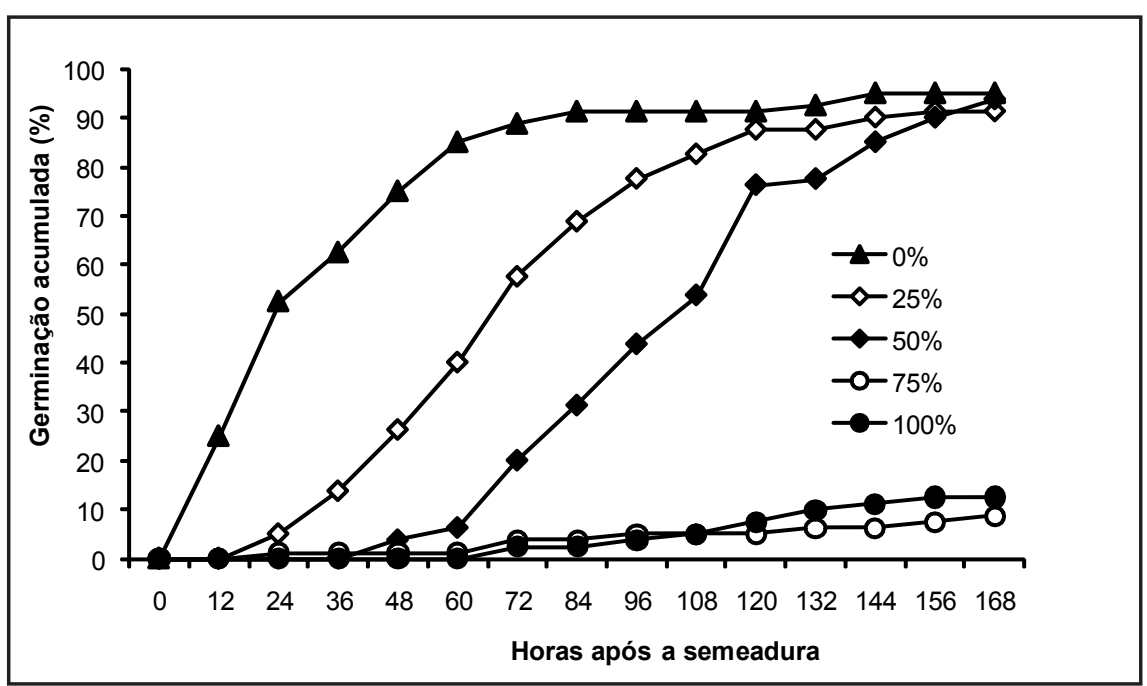

Figura 1. Curvas germinativas de sementes de alface submetidas a diversas concentrações de extrato de sementes de juazeiro (germination curves of lettuce seeds submitted to diverse concentrations of juazeiro seed extract). Mossoró, UFERSA, 2008.

raiz primária é o sintoma mais comum da anormalidade (Ferreira \& Aquila, 2000). Muitas vezes, o efeito alelopático não se dá pela germinabilidade, mas sobre a velocidade de germinação ou sobre outro parâmetro do processo (Ferreira \& Borghetti, 2005).

As curvas de germinação mostradas na Figura 1 confirmam este efeito. Após $24 \mathrm{~h}$ da semeadura $50 \%$ das sementes da testemunha já haviam germinado enquanto nas menores concentrações do extrato a germinação foi lenta e nas maiores atingiu menos de $13 \%$ no final do experimento. Peres et al. (1998) observaram o mesmo comportamento germinativo de Clidemia hirta submetida a extratos de Gleichenia pectinata, que provocaram um nítido retardo no tempo da germinação.

Assim como foi observado o efeito alelopático do extrato de sementes de juazeiro no comportamento germinativo de alface, Miró et al. (1998) também verificaram que os possíveis aleloquímicos presentes em frutos maduros de erva-mate (Ilex paraguariensis) causaram o mesmo efeito em sementes de alface, além de reduzir a altura da planta, comprimento do primeiro entrenó, massa seca da parte aérea e da raiz, comprimento das folhas, número de raízes adventícias e comprimento da raiz primária.

Ono et al. (2004) observaram que as sementes de mamão, apresentam dificul- dade para germinar devido à ocorrência de substâncias inibidoras presentes no arilo, e Balsalobre et al. (2005) verificaram que o maracujazeiro também apresenta substancias alelopáticas no seu arilo. O juazeiro apresenta sementes envolvidas por uma mucilagem, e vários autores (Alves et al., 2006; Alves et al., 2008; Moniz-Brito \& Osuna, 2008) relataram a baixa capacidade de germinação atribuída à dormência de suas sementes. A unidade de dispersão do juazeiro consiste de um diásporo composto da semente (1 a 2) e de um complexo orgânico que a acompanha, no caso, um endocarpo pétreo e extremamente resistente. Segundo Moniz-Brito \& Osuna (2008), encontrar plântulas dessa espécie próximas às plantas matrizes é extremamente raro. Os efeitos alelopáticos verificados no presente trabalho podem ser uma explicação para estes fatos, sendo necessários ainda outros estudos para determinar a natureza dos aleloquímicos.

\section{AGRADECIMENTOS}

Os autores Andreya K Oliveira e Francisco EP Diógenes agradecem o apoio financeiro recebidos do PIBIC, CNPq e UFERSA.

\section{REFERÊNCIAS}

AIRES SS; FERREIRA AG; BORGHETTI F.
2005. Efeito alelopático de folhas e frutos de Solanum lycocarpum A. St.-Hil. (Solanaceae) na germinação e crescimento de Sesamun indicum L.(Pedaliaceae) em solo sob três temperaturas. Acta Botanica Brasílica 19: 339-344.

ALVES EU; BRAGA JÚNIOR JM; BRUNO RLA; OLIVEIRA AP; CARDOSO EA; ALVES AU; SILVA KB. 2008. Métodos para quebra de dormência de unidades de dispersão de Zizyphus joazeiro Mart. (Rhamnaceae). Revista Arvore 32: 407-415.

ALVES EU; BRUNO RLA; OLIVEIRA AP; ALVES AU. 2006. Ácido sulfúrico superação da dormência de unidade de dispersão de juazeiro (Zizyphus joazeiro Mart.). Revista Árvore 30: 187-195.

BALSALOBRE LC; GUTIERREZ RC; COMARIN MT; GOUVEIA MC; PINTO DG; PEREIRA BM. 2005. Ação alelopática do arilo das sementes de Passiflora edulis Sims e Passiflora alata Dryand. In: Anais do VIII Simpósio de Ciências Biológicas, São Paulo. VIII Simpósio de Ciências Biológicas. São Paulo, p. 13.

BORGES EEL; LOPES ES; SILVA GF. 1993. Avaliação de substâncias alelopáticas em vegetação de uma floresta secundária. 1Árvores. Revista Árvore 17: 69-84.

BRASIL. 1992. Ministério da Agricultura e Reforma Agrária. Regras para análise de sementes. Brasília: Coordenação de Laboratório Vegetal, Departamento de Defesa Vegetal, 365p.

CARMO FMS; BORGES EEL; TAKAKI MM. 2007. Alelopatia de extratos aquosos de canelasassafrás (Ocotea odorifera (Vell.) Rohwer). Acta Botanica Brasilica 21: 697-705.

FELIX RAZ; ONO EO; SILVA CP; RODRIGUES JD; PIERI C. 2007. Efeitos alelopáticos da Amburana cearensis L. (Fr.All.) AC Smith na germinação de sementes de alface (Lactuca sativa L.) e de rabanete (Raphanus sativus L.). Revista Brasileira de Biociências 5: 138-140.

FERREIRAAG; ÁQUILAMEA. 2000. Alelopatia: uma área emergente da ecofisiologia. Revista Brasileira de Fisiologia Vegetal 12: 175-204, Edição especial.

FERREIRA AG; BORGHETTI F. 2005. Germinação: do básico ao aplicado. Porto Alegre: Artmed, 323p.

FERREIRA MC; SOUZA JRP; FARIA TJ. 2007. Potenciação alelopática de extratos vegetais na germinação e no crescimento inicial de picão-preto e alface. Ciência Agrotecnica 31: 1054-1060.

FRANÇA AC; SOUZA IF; SANTOS CC; OLIVEIRA EQ; MARTINOTTO C. 2008. Atividades alelopáticas de nim sobre o crescimento de sorgo, alface e picão-preto. Ciência Agrotecnica 32: 1374-1379.

GATTI AB; PEREZ SCJGA; LIMA MIS. 2004. Efeito alelopático de Aristolochia esperanzae O. Kuntze na germinação e no crescimento de Lactuca sativa L. e Raphanus sativus L. Acta Botânica Brasilica 18: 459-472.

GONZÁLES L; SOUTO XC; REIGOSAMJ. 1995. Allelopathic effects of Acacia melanoxylon $\mathrm{R}$. Br. Phyloides during their decomposition. 
Forest Ecology Management 77: 53-63.

GUSMAN GS; BITTENCOURT AHC; VESTENA S. 2008 Alelopatia de Baccharis dracunculifolia DC. sobre a germinação e desenvolvimento de espécies cultivadas. Acta Scientiarum 30: 119-125.

HARTMANN TH; KESTER DE; DAVIES JRFT; GENEVE R. 2001. Plant propagation: principles and practices. 7 ed. New York: Prentice Hall, 880p.

JACOBI US; FERREIRA AG. 1991. Efeitos alelopáticos de Mimosa bimicronata (DC). sobre espécies cultivadas. Pesquisa Agropecuaria Brasileira 26: 935-943.

LORENZI H; MATOS FJA. 2002. Plantas medicinais no Brasil: nativas e exóticas. Nova Odessa: Plantarum. 512p.

MAGUIRE JD. 1962. Speed of germination-aid in selection evaluation for seedling emergence and vigor. Crop Science 2: 176-177.

MARASCHIN-SILVA F; ÁQUILA MEA. 2005. Potencial alelopático de Dodonaea viscosa (L.) Jacq. Iheringia, Série Botanica 60: 91-98.

MARASCHIN-SILVA F; AQUILA MEA. 2006. Contribuição ao estudo do potencial alelopático de espécies nativas. Revista Árvore 30: 547-555.

MATOS FJA. 2000. Plantas medicinais. Guia de seleção e emprego de plantas usadas em fitoterapia no Nordeste do Brasil. 2. ed. Fortaleza: UFC. 346p.

MIRÓ CP; FERREIRA AG; AQUILA MEA. 1998. Alelopatia de frutos de erva-mate (llex paraguariensis) no desenvolvimento do milho. Pesquisa Agropecuária Brasileira 33: 1261-1270.

MONIZ-BRITO KL; OSUNA JTA. 2008. Influência dos tratamentos físicos e químicos na germinação de Ziziphus joazeiro Mart. (Rhamnaceae). Magistra 20: 16-21.

MOREIRA PFSD; SOUZA DR; TERRONES MGH. 2009. Avaliação do potencial alelopático do extrato metanólico obtido das folhas de Caryocar brasiliense Camb. (pequi) na inibição do desenvolvimento da raiz em sementes de Panicum maximum. Bioscience Journal 24: 74-79.

NADIA TL; MACHADO IC; LOPES AV. 2007. Fenologia reprodutiva e sistema de polinização de Ziziphus joazeiro Mart. (Rhamnaceae): atuação de Apis mellifera e de visitantes florais autóctones como polinizadores. Acta Botanica Brasilica 21: 835-845.

ONO EO; JÚNIOR JFG; RODRIGUES JD. 2004. Reguladores vegetais na quebra da dominância apical de mamoeiro (Carica papaya L.). Revista Brasileira de Fruticultura 26.

PERES MTLP; PIZZOLATTI MG; QUEIROZ MH; YUNES RA. 1998. Potencial de atividade alelopática de Gleichenia pectinata WILLD (PR.) Pesquisa Agropecuária Brasileira 33: 131-137.

RIBEIRO JÚNIOR JI. 2001. Análises estatísticas no SAEG. Viçosa: Universidade Federal de Viçosa, 301 p.

RICE EL. 1984. Allelopathy. $2^{\text {nd }}$ ed. New York: Academic Press.

SARTOR LR; CHINI PFAN; MARTIN TN; MARCHESE JA; SOARES AB. 2009. Alelopatia de acículas de Pinus taeda na germinação e no desenvolvimento de plântulas de Avena strigosa. Ciência Rural 39: 16531659.

SILVA GB; MARTIM L; SILVA CL; YOUNG MCM; LADEIRA AM. 2006. Potencial alelopático de espécies arbóreas nativas do Cerrado. Hoehnea33: 331-338.

SOUZA SAM; CATTELAN LV; VARGAS DP; PIANA CFB; BOBROWSKI VL; ROCHA BHG. 2005. Efeito de extratos aquosos de plantas medicinais nativas do Rio Grande do Sul sobre a germinação de sementes de alface. Publ. UEPG Ci. Biol. Saúde 11: 29-38.

TAIZ L; ZEIGER E. 2004. Fisiologia vegetal. 3. ed. Porto Alegre: Artmed, 719 p.

ZHANG Q. 1993. Potential role of allelopathy in the soil and the decomposition root of chinese-fir replant woodland. Plant Soil 151: 205-209. 